Article

\title{
Effect of Superheated Steam Treatment on the Mechanical Properties and Dimensional Stability of PALF/PLA Biocomposite
}

\author{
Ahmed Jaafar Hussein Challabi ${ }^{1}$, Buong Woei Chieng ${ }^{1,2, * \mathbb{D}}$, Nor Azowa Ibrahim ${ }^{1,2, * \mathbb{D} \text {, }}$ \\ Hidayah Ariffin ${ }^{3}$ (D) and Norhazlin Zainuddin ${ }^{1}$ \\ 1 Department of Chemistry, Faculty of Science, Universiti Putra Malaysia, 43400 UPM Serdang, Selangor, \\ Malaysia; ahmed.challabi@yahoo.com (A.J.H.C.); norhazlin@upm.edu.my (N.Z.) \\ 2 Materials Processing and Technology Laboratory, Institute of Advanced Technology, \\ Universiti Putra Malaysia, 43400 UPM Serdang, Selangor, Malaysia \\ 3 Department of Bioprocess Technology, Faculty of Biotechnology and Biomolecular Sciences, \\ Universiti Putra Malaysia, 43400 UPM Serdang, Selangor, Malaysia; hidayah@upm.edu.my \\ * Correspondence: chieng891@gmail.com (B.W.C.); norazowa@upm.edu.my (N.A.I.); \\ Tel.: +603-9769-6802 (B.W.C.); +603-9769-4205 (N.A.I.)
}

Received: 7 January 2019; Accepted: 10 February 2019; Published: 13 March 2019

\begin{abstract}
The effectiveness of superheated steam (SHS) as an alternative, eco-friendly treatment method to modify the surface of pineapple leaf fiber (PALF) for biocomposite applications was investigated. The aim of this treatment was to improve the interfacial adhesion between the fiber and the polymer. The treatment was carried out in an SHS oven for different temperatures $\left(190-230{ }^{\circ} \mathrm{C}\right)$ and times (30-120 min). Biocomposites fabricated from SHS-treated PALFs and polylactic acid (PLA) at a weight ratio of 30:70 were prepared via melt-blending techniques. The mechanical properties, dimensional stability, scanning electron microscopy (SEM), and X-ray diffraction (XRD) for the biocomposites were evaluated. Results showed that treatment at temperature of $220{ }^{\circ} \mathrm{C}$ for $60 \mathrm{~min}$ gave the optimum tensile properties compared to other treatment temperatures. The tensile, flexural, and impact properties as well as the dimensional stability of the biocomposites were enhanced by the presence of SHS-treated PALF. The SEM analysis showed improvement in the interfacial adhesion between PLA and SHS-treated PALF. XRD analysis showed an increase in the crystallinity with the addition of SHS-PALF. The results suggest that SHS can be used as an environmentally friendly treatment method for the modification of PALF in biocomposite production.
\end{abstract}

Keywords: superheated steam; pineapple leaf; biocomposite

\section{Introduction}

There has recently been growing interest in natural fibers due to their ability to reinforce polymers and replace synthetic fibers in the fabrication of composites or biocomposites. The widespread application of natural fibers can be attributed to their many advantages, such as being environmentally friendly, low cost, nontoxic, renewable, and having high strength. Natural fibers, such as hemp, flax, jute, oil palm, and kenaf, have been utilized in a variety of composite applications, including automotive, construction, and aerospace [1,2]. Another study reported the incorporation of natural fiber composites in the car industry for both interior and exterior car parts [3].

Malaysia ranks ninth in the world among the exporter countries for pineapple, with 425,019.75 metric ton of total production annually [4]. Pineapple leaf fibers (PALF) are one of the waste materials in the agriculture sector, with very large production in Malaysia as well as in Asia. Pineapple leaf fibers have been used to reinforce polymers in composite fabrication due to their high strength and good 
mechanical properties compared to other natural fibers [5]. Moreover, pineapple leaf fibers contain high amounts of cellulose, which may attribute to their good mechanical properties. The chemical composition of pineapple leaf fibers was reported by Jose et al. [6] as $80 \%-81 \%$ cellulose, $16 \%-19 \%$ hemicellulose, and $4.6 \%-12 \%$ lignin. In addition, pineapple leaf fibers have been used to reinforce polymers in biocomposite fabrication and shown to make a significant improvement in the mechanical and thermal properties of the biocomposites $[7,8]$.

Polylactic acid (PLA) is a biodegradable thermoplastic polymer that comes from renewable natural resources, such as corn starch and sugar cane. The two most common methods for PLA synthesis are ring-opening polymerization and condensation [9]. PLA is used in a variety of applications due to its good mechanical properties, good biodegradability, and biocompatibility [10]. However, PLA still has some drawbacks, such as high cost, brittleness, and poor toughness. Attempts to overcome these issues have included blending PLA with other polymers, modifying PLA with plasticizer, and blending PLA with inorganic nanofillers [11].

In a previous study, PALF was used to reinforce PLA via melt-blending techniques [12]. However, there were some drawbacks due to poor interfacial adhesion between the fiber and the matrix resulting from the hydrophilic nature of PALF and the hydrophobicity nature of PLA. Thus, attempts have been made to modify the fiber surface in order to improve the interfacial adhesion. Most of these modification methods used chemical treatment, such as alkali with $\mathrm{NaOH}$ [13-15], bleaching [9], chemical grafting [16], or silane [17]. All these modification methods improved the biocomposite properties, but most of the methods are not eco-friendly as they use chemicals or are toxic and expensive. Therefore, there is still a need for a cheap and environmentally friendly modification method.

Superheated steam (SHS) has recently been used as an alternative to other chemical treatment methods. SHS is a steam produced by boiling wet steam with additional heat at a given pressure, which can be used in drying processes [18]. It is a cheap and eco-friendly treatment for surface modification of fibers because as water is the only element used in this technique [19]. Thus, it can be a cost-effective method with low risk. Superheated steam has been applied for lignocellulosic materials in various applications, for example, biofuel production, activated carbon, and bioabsorbents among others [20]. Furthermore, studies have shown the ability of SHS treatment to remove hemicellulose particles, which can attribute to the increase in cellulose and lignin content in fibers [21]. Another study by Hosseinaei et al. [22] showed an increase in fiber hydrophobicity and thermal stability attributed to the removal of hemicellulose. All the above properties can be advantageous in biocomposite production. For this reason, superheated steam is a promising alternative treatment method for the modification of fibers in biocomposite fabrication. To the best of our knowledge, there has not been any previous study on the utilization of SHS to modify PALF.

Based on the described issues, the main objective of this work was the modification of PALF surface. Fourier transform infrared (FTIR) spectroscopy and scanning electron microscopy (SEM) were used for the characterization of the treated fiber. The effect of SHS-treated PALF on the mechanical properties and dimensional stability of PALF/PLA biocomposites were then examined.

\section{Materials and Methods}

\subsection{Materials}

PLA was purchased from Natureworks LLC (Minnetinka, MN, USA) under the trade name polylactide resin 3052D. It has a density of $1.24 \mathrm{~g} / \mathrm{cm}^{3}$, melting point range between 170 and $190{ }^{\circ} \mathrm{C}$, and a molecular weight of 93,500 g/mol. PALF was procured from Nature Renascent (Johor Bahru, Malaysia). It was supplied in bundles of long fibers, which was then dried under sunlight and ground, sieved into sizes of 300-500 $\mu \mathrm{m}$, and kept in sealed plastic bags. Table 1 present the chemical composition of PALF. 
Table 1. Chemical composition of the raw pineapple leaf fiber (PALF).

\begin{tabular}{cccc}
\hline Fiber & Cellulose (\%) & Hemicellulose (\%) & Lignin (\%) \\
\hline PALF & 69.89 & 19.67 & 10.43 \\
\hline
\end{tabular}

\subsection{Modification of PALF by SHS Treatment}

Modification of PALF by SHS was carried out in a superheated steam oven (Model QF-5200C, Naomoto Corporation, Osaka, Japan) under normal pressure following the methods described by Then et al. [19] and Nordin et al. [23]. Tap water was used to produce SHS. PALF was dried in an oven at $60{ }^{\circ} \mathrm{C}$ before the treatment. The dried PALF was then treated with SHS oven at temperature of 190, $200,210,220$, and $230^{\circ} \mathrm{C}$ for $60 \mathrm{~min}$. The experiment procedure was as follows. First, the SHS oven was turned on and allowed to reach a steady state of the desired condition. Next, PALF was spread on an aluminum foil tray. It was then put into the heating chamber of the SHS oven under the set condition. Once the treatment was complete, the fiber was removed immediately from the heating chamber and cooled down in a desiccator before being placed in a sealed plastic bag. The PALF treated at $220^{\circ} \mathrm{C}$ showed the best tensile results for the biocomposite compared to other treatment temperatures. Therefore, it was chosen to conduct further experiment with the same treatment procedures at different treatment times $(30,90$, and $120 \mathrm{~min})$ to determine the best treatment time.

\subsection{Fabrication of Biocomposites}

To prepare a biocomposites, the oven-dried PALF, together with PLA, was prepared by the melt-blending technique using Brabender Internal Mixer at $160{ }^{\circ} \mathrm{C}$ with $50 \mathrm{rpm}$ of rotor speed and for $15 \mathrm{~min}$, as the method described by Birnin-Yauri et al. [24]. First, the PLA pellets were put into the mixing chamber to melt for $2 \mathrm{~min}$. Then, the fibers were added, and the blending was continued for $13 \mathrm{~min}$, followed by compression molding to produce sheets with thickness of $1 \mathrm{~mm}$ and $3 \mathrm{~mm}$. Compression molding was performed using a hydraulic hot press at $160^{\circ} \mathrm{C}$ molding temperature, $150 \mathrm{~kg} / \mathrm{cm}^{2}$ pressure, and for $5 \mathrm{~min}$. After that, cooling was performed at $30^{\circ} \mathrm{C}$ for $5 \mathrm{~min}$.

\subsection{Characterizations}

\subsubsection{Fourier Transform Infrared (FTIR) Spectroscopy}

The functional groups and the chemical components of the untreated PALF and SHS-PALF were identified by FTIR using Perkin Elmer Model 100 series (Waltham, MA, USA) equipped with attenuated total reflectance (ATR). The FTIR spectra of the samples were recorded in the wavenumber ranging $400-4000 \mathrm{~cm}^{-1}$.

\subsubsection{Mechanical Properties}

A tensile property test was performed using Universal Testing Machine Instron Model 5566. Five specimens were tested following the ASTM D638 (type V). The test was conducted at room temperature with $1 \mathrm{kN}$ load cell and a constant crosshead speed of $10 \mathrm{~mm} / \mathrm{min}$. The tensile strength, tensile modulus, and elongation at break were obtained from the test.

A three-point bending test was conducted on the biocomposites using Universal Testing Machine Instron Model 5566. Five specimens were tested using ASTM D790, with the test conducted at $25^{\circ} \mathrm{C}$ with $1 \mathrm{kN}$ load. The results were expressed in terms of flexural strength and flexural modulus.

The impact strength of the biocomposites was tested using an un-notched Izod impact test. The impact tester (Mumbai, India) was equipped with a $7.5 \mathrm{~J}$ pendulum. The test was conducted at $25^{\circ} \mathrm{C}$, and five specimens were tested using the ASTM D256 with dimension size $63.5 \times 12.7 \times$ $3.0 \mathrm{~mm}^{3}$. The impact strength $(\mathrm{J} / \mathrm{m})$ was calculated by dividing the energy $(\mathrm{J})$ obtained with the thickness $(\mathrm{m})$ of the specimen. 


\subsubsection{Scanning Electron Microscopy}

The scanning electron micrographs of the tensile fracture surface of PALF and SHS-PALF were recorded using a JEOL (Tokyo, Japan) JSM-6400 scanning electron microscope operated at $15 \mathrm{kV}$ accelerating voltage. The samples were first oven-dried, then put on a metal holder and coated with gold using a Bio-rad (Hercules, CA, USA) coating system for $3 \mathrm{~min}$ to ensure better conductivity prior to analysis.

\subsubsection{X-Ray Diffraction (XRD) Analysis}

The crystallinity of neat PLA and PALF/PLA and SHS-PALF/PLA biocomposites were analyzed using a Shimadzu XRD 600 diffractometer (Tokyo, Japan) with a nickel-filtered $\mathrm{Cu} \mathrm{K} \alpha(\lambda=0.1542 \mathrm{~nm})$ beam performed at $30 \mathrm{kV}$ and $30 \mathrm{~mA}$. The samples were examined with a scanning rate of $2^{\circ} / \mathrm{min}$ at $25^{\circ} \mathrm{C}$ within a $2 \theta$ range of $10^{\circ}$ to $60^{\circ}$.

\subsubsection{Dimensional Stability Measurement}

Water uptake and thickness swelling of the biocomposites were determined according to the ASTM D570 and European Standard EN 317 (1993), respectively. Samples with dimension of $10.0 \times$ $10.0 \times 1.0 \mathrm{~mm}^{3}$ were cut from the sample sheets and used for testing. Prior to the testing, the samples were dried in an oven at $60{ }^{\circ} \mathrm{C}$ until a constant weight was obtained. The initial weight $\left(\mathrm{W}_{0}\right)$ and thickness $\left(\mathrm{T}_{0}\right)$ of the dried samples were measured, and the samples were then soaked in distilled water for $24 \mathrm{~h}$ at $25^{\circ} \mathrm{C}$. After that, the samples were removed and wiped with tissue paper to remove excess water on the surface of the samples. The final weight $\left(\mathrm{W}_{24 \mathrm{~h}}\right)$ and thickness $\left(\mathrm{T}_{24 \mathrm{~h}}\right)$ of the samples were measured immediately. Five specimens were tested, and the average value and standard deviation were calculated. The water uptake and thickness swelling of the biocomposites were calculated based on Equations (1) and (2), respectively:

$$
\begin{gathered}
\text { Water uptake }(\%)=\frac{\mathrm{w}_{24 \mathrm{~h}}-\mathrm{w}_{0}}{\mathrm{w}_{0}} \times 100 \\
\text { Thickness swelling }(\%)=\frac{\mathrm{T}_{24 \mathrm{~h}}-\mathrm{T}_{0}}{\mathrm{~T}_{0}} \times 100
\end{gathered}
$$

\section{Results and Discussion}

\subsection{Characterization of PALF and SHS-PALF}

\subsubsection{Fourier Transform Infrared (FTIR) Analysis}

The FTIR was used to locate and observe the functional group and chemical components of the fiber. The FTIR spectra in Figure 1 represent the untreated PALF and SHS-treated PALF with treatment temperature of $220^{\circ} \mathrm{C}$ for $60 \mathrm{~min}$, which was shown to have the best tensile properties for the biocomposite (discussed in Section 3.2.1). The most significant difference that can be seen in the FTIR spectra is the peak at $1724 \mathrm{~cm}^{-1}$, which corresponds to the acetyl group and $\mathrm{C}=\mathrm{O}$ bond and represents the hemicellulose characterization. The absence of this peak for SHS-treated fiber can also be observed, indicating the removal of the hemicellulose for the SHS-treated PALF. A similar observation was reported by Sena Neto et al. [25]. In addition, a reduction occurred in the hydrophilicity of SHS-PALF in comparison to the untreated PALF, which was confirmed by the decrease in the absorbance of peak at $1632 \mathrm{~cm}^{-1}$, which corresponds to $\mathrm{OH}$ stretching of absorbed water [26]. Moreover, there was an absence of the peak at $1248.98 \mathrm{~cm}^{-1}$ in the case of SHS-PALF. This peak is attributed to the C-O stretching in acetyl in xylan, and the absence was due to the removal of the acetyl groups presented in the hemicellulose [27]. 


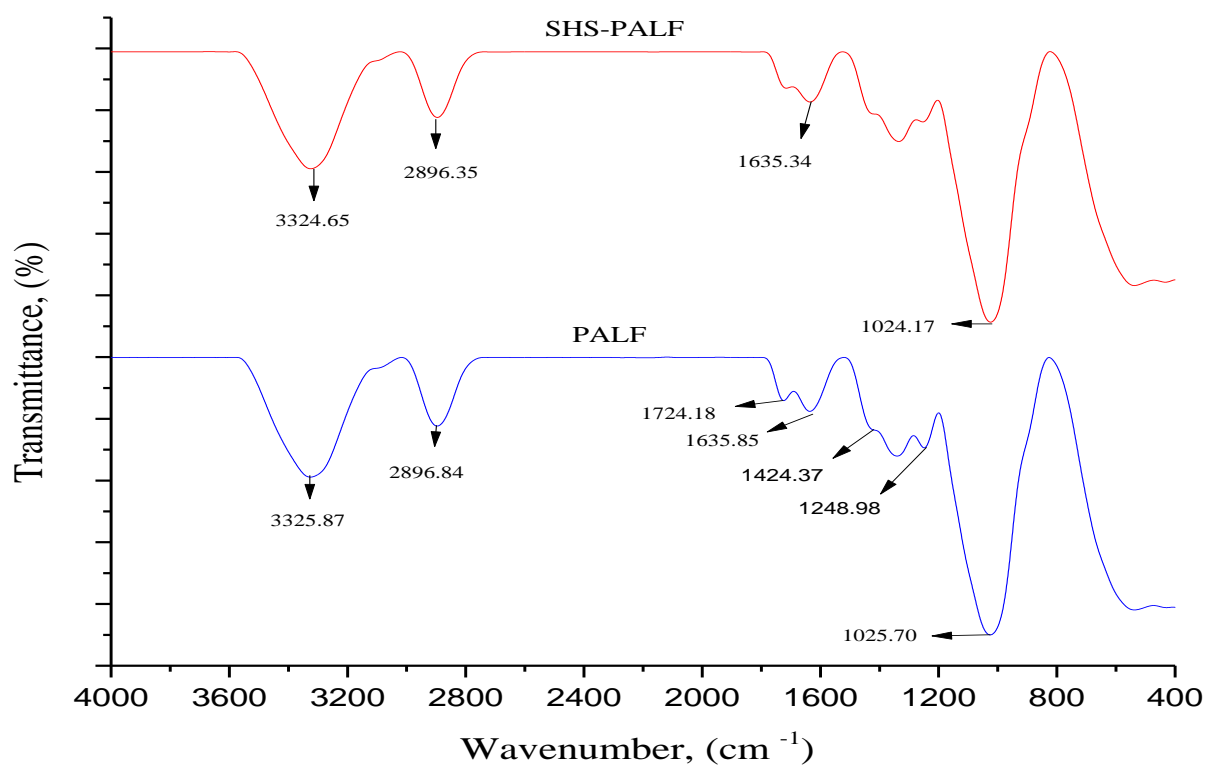

Figure 1. FTIR spectra of PALF and superheated steam-treated PALF (SHS-PALF).

\subsubsection{Surface Morphology}

Figure 2 presents the surface morphology from the SEM analysis for the untreated PALF and SHS-treated PALF with treatment temperature of $220^{\circ} \mathrm{C}$ for $60 \mathrm{~min}$, which was has shown to have the best tensile properties for the biocomposite (discussed in Section 3.2.1). The untreated PALF, shown in Figure 2a, had a smooth surface covered with impurities and some waxy substances. A similar observation was reported by Dong et al. [28]. However, after SHS treatment, it could be observed that the treated PALF, shown in Figure 2b, did not have these impurities, and the fiber surface became rougher. A similar observation was reported by Panyasart et al. [29].
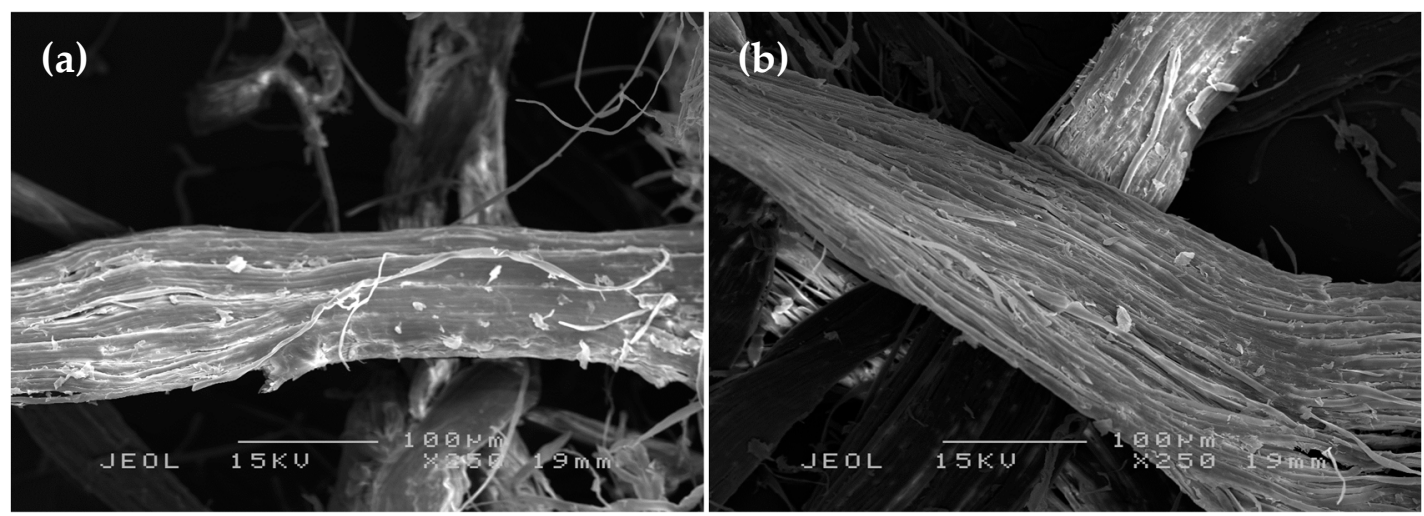

Figure 2. SEM micrographs of (a) 250x PALF and (b) 250x SHS-PALF.

The SEM and FTIR analyses demonstrated the ability of SHS treatment to improve the fiber's properties by removing the surface impurities and making the fiber surface rougher for better interfacial adhesion between the fiber and the polymer. A similar observation was reported for PALF treated with $\mathrm{NaOH}$, which was shown to improve the properties of the fiber [13]. However, the SHS treatment can be classified as more environmentally friendly modification method in comparison to $\mathrm{NaOH}$ treatment as no chemicals are used during the process of fiber treatment. Moreover, the fiber that has been modified by SHS treatment can be utilized without any drying process for biocomposite fabrication. Thus, SHS can be used as an alternative to $\mathrm{NaOH}$ treatment for fiber modification. 


\subsection{Characterization of Untreated PALF/PLA and SHS-PALF/PLA Biocomposites}

\subsubsection{Tensile Properties}

In this work, PLA was used as the polymer matrix due to its good mechanical and environmental properties. PLA has been previously reported by Birnin-Yauri et al. [30] to have high strength, modulus, and biocompatibility. The fiber-matrix ratio in the biocomposite is 30:70 according to previous studies done on PALF biocomposites [31].

SHS was used as a treatment method to improve the surface adhesion between PLA and PALF. The effectiveness of SHS was evaluated by comparing the tensile results for the untreated fiber and treated fiber. Table 2 presents the results of tensile strength (TS), elongation at break (EB), and tensile modulus (TM) for the biocomposites. The neat PLA results showed a reduction in the mechanical properties after adding the natural fibers.

Table 2. Mechanical properties of PALF/PLA and SHS-PALF/PLA biocomposites.

\begin{tabular}{cccccc}
\hline & $\begin{array}{c}\text { Treatment } \\
\text { Temperature } \\
{ }^{\circ} \mathbf{C}\end{array}$ & $\begin{array}{c}\text { Treatment } \\
\text { Time } \\
(\mathbf{m i n})\end{array}$ & $\begin{array}{c}\text { Tensile } \\
\text { Strength } \\
\mathbf{( M P a )}\end{array}$ & $\begin{array}{c}\text { Elongation } \\
\text { at Break } \\
\mathbf{( \% )}\end{array}$ & $\begin{array}{c}\text { Tensile } \\
\text { Modulus } \\
\mathbf{( G P a )}\end{array}$ \\
\hline PLA & - & - & $63.54 \pm 0.11$ & $6.64 \pm 0.30$ & $1.14 \pm 0.05$ \\
PALF/PLA & - & - & $46.82 \pm 1.75$ & $3.67 \pm 0.17$ & $1.39 \pm 0.02$ \\
& 190 & 60 & $46.69 \pm 1.13$ & $3.55 \pm 0.09$ & $1.58 \pm 0.07$ \\
& 200 & 60 & $50.24 \pm 1.40$ & $3.84 \pm 0.17$ & $1.59 \pm 0.06$ \\
& 210 & 60 & $50.01 \pm 1.13$ & $3.73 \pm 0.20$ & $1.56 \pm 0.03$ \\
SHS-PALF/PLA & & 30 & $53.01 \pm 1.33$ & $3.75 \pm 0.17$ & $1.63 \pm 0.05$ \\
& 220 & 60 & $57.94 \pm 1.51$ & $4.18 \pm 0.19$ & $1.61 \pm 0.03$ \\
& & 90 & $52.1 \pm 1.60$ & $3.85 \pm 0.00$ & $1.61 \pm 0.04$ \\
& 230 & 120 & $51.43 \pm 2.14$ & $3.67 \pm 0.17$ & $1.81 \pm 0.09$ \\
& & 60 & $41.20 \pm 1.32$ & $2.97 \pm 0.17$ & $1.54 \pm 0.01$ \\
\hline
\end{tabular}

As can be seen from Table 2, at the treatment time of $60 \mathrm{~min}$ and treatment temperature of $190{ }^{\circ} \mathrm{C}$, the TS and EB for treated PALF remained almost the same as the untreated PALF, while there was an improvement in $\mathrm{TM}$ of $13 \%$. The increase in TS, EB, and TM occurred with the increase in the treatment temperature from 200 to $220^{\circ} \mathrm{C}$ and decreased at $230{ }^{\circ} \mathrm{C}$. At $220^{\circ} \mathrm{C}$, the improvement in TS and EB were recorded as $24 \%$ and $14 \%$, respectively, compared to the untreated PALF. The TM increased with the increase in treatment temperature up to $220^{\circ} \mathrm{C}$, reached the highest value at $220{ }^{\circ} \mathrm{C}$ for $120 \mathrm{~min}$, then decreased at $230{ }^{\circ} \mathrm{C}$. At $220^{\circ} \mathrm{C}$ for $60 \mathrm{~min}$, the increase in TM was $16 \%$ in comparison to that of the untreated PALF. It is obvious from the table that the TS was optimum at $220^{\circ} \mathrm{C}$ for $60 \mathrm{~min}$, as were the EB and the TM, in comparison to the untreated PALF/PLA. Thus, this temperature was selected to conduct further experiments in order to determine the optimum time for this treatment.

Figure 3 shows typical tensile curves of PALF/PLA and SHS-PALF/PLA biocomposites with treatment condition of $220{ }^{\circ} \mathrm{C}$ and $60 \mathrm{~min}$. The figure clearly shows that both tensile stress and elongation improved for the SHS-PALF/PLA biocomposite compared to the PALF/PLA one and that the SHS-PALF/PLA biocomposite had slightly better stiffness compared to the PALF/PLA biocomposite. 


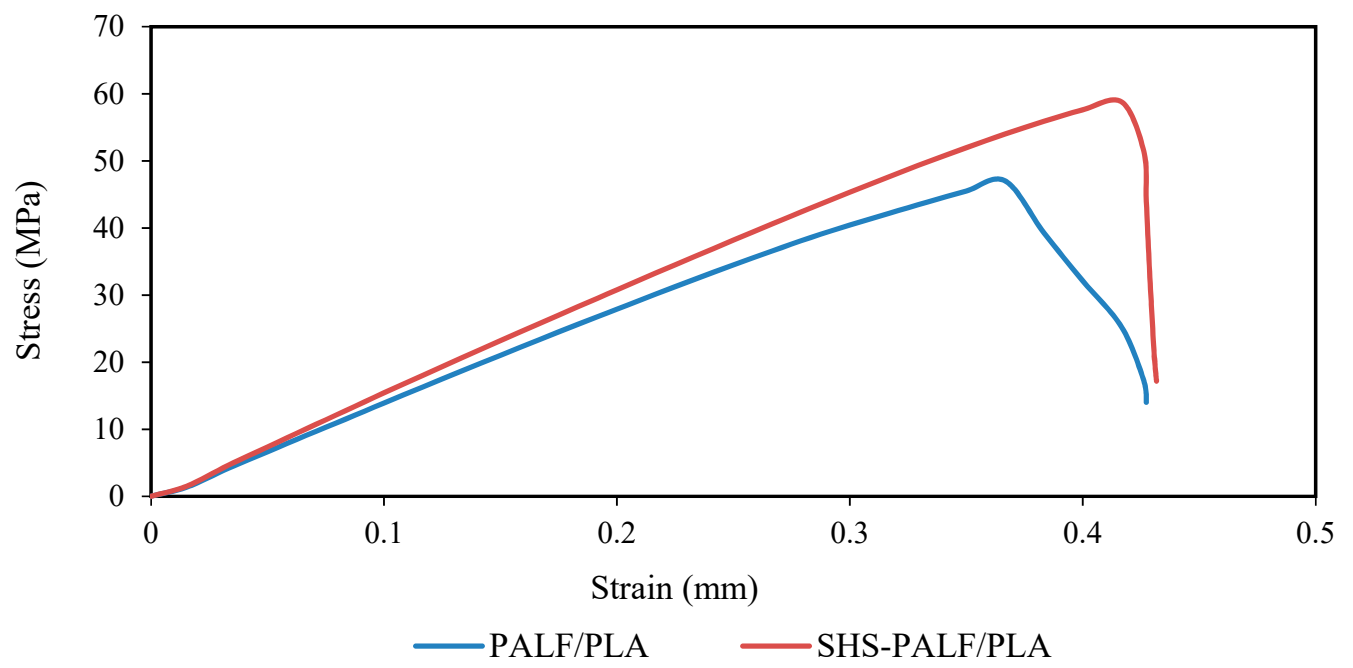

Figure 3. Typical tensile curves for PALF/PLA and SHS-PALF/PLA biocomposites.

The TS and EB increased at 60 min treatment time compared to other treatment times, but decreased and remained stable for other treatment times (30, 90, $120 \mathrm{~min})$. However, TM was also stable from 60 to $90 \mathrm{~min}$, and it reached its highest value at $120 \mathrm{~min}$ with $30 \%$ improvement compared to the untreated PALF and 12\% improvement compared to $60 \mathrm{~min}$ treatment time. From the tensile results, it could be concluded that treated PALF at $220{ }^{\circ} \mathrm{C}$ and $60 \mathrm{~min}$ gave the best biocomposite with the optimum TS, EB, and TM compared to the untreated PALF as well as to other treatment temperatures and times.

As can be seen, SHS treatment improved the tensile properties in the PALF/PLA biocomposite. This might have been due to the removal of impurities on the fiber surface in the case of SHS-PALF, as shown in Section 3.1.2, which led to a rough fiber surface, thus promoting a better interfacial bonding and additional improvement in mechanical interlocking between the matrix and fibers [32]. Moreover, there was a gradual increase in the fiber hydrophobicity of SHS-PALF from 200 to $220{ }^{\circ} \mathrm{C}$ due to the reduction in water absorption of the fiber [33]. This might have resulted in better compatibility with the hydrophobic PLA, which improved the tensile properties of the biocomposite. As has been previously reported, SHS treatment works by removing the hemicellulose from the fiber and changing the chemical compound of the fiber by increasing the cellulose and lignin content [23]. It was observed that, at 200 to $220^{\circ} \mathrm{C}$ treatment temperature, there was an enhancement in the tensile strength with the removal of hemicellulose from the fiber. This led to an improvement in the mechanical performance of the biocomposite [34]. Moreover, the best value for elongation at break was at $220^{\circ} \mathrm{C}$ and $60 \mathrm{~min}$, indicating that, the interfacial bonding of the SHS-PALF/PLA biocomposite was strong at this treatment temperature. A similar observation can be made for the reduction of tensile strength with high treatment temperature of $230^{\circ} \mathrm{C}$. Here, the degradation of hemicellulose would occur rapidly by liberation of large amount of acetic acid [19]. This may accumulate on the fiber surface and accelerate the degradation process of cellulose. Thus, it will affect the mechanical strength of the biocomposite.

\subsubsection{Fracture Surface Morphology}

The tensile fracture surface of PALF/PLA and SHS-PLAF/PLA with treatment temperature of $220^{\circ} \mathrm{C}$ and $60 \mathrm{~min}$ were examined under scanning electron microscope in order to study the adhesion between the fiber and the matrix. As shown in Figure 4a,b, the untreated PALF and PLA had poor interfacial adhesion due to the incompatibility between the hydrophilic PALF and the hydrophobic PLA. Furthermore, the voids were visible in the structure of the biocomposite, and those voids between the two phases led to poor adhesion and decrease in properties [35]. However, the morphology for the SHS-PALF/PLA biocomposite, given in Figure 4c,d, showed a better interfacial adhesion compared to 
the untreated PALF/PLA biocomposite and looked solid in structure. Moreover, there were no visible voids on the surface of the biocomposite, with rougher fiber surface, which led to a better compatibility between PALF and PLA [36].


Figure 4. SEM micrographs of PALF/PLA (a) 250x, (b) 500x; and SHS-PALF/PLA (c) 250x, (d) $500 \mathrm{x}$ biocomposites.

Additionally, it has been reported that lignin softens within a temperature range of $160-190{ }^{\circ} \mathrm{C}$ [19]; below this temperature, lignin is in solid phase. When lignin softens, it turns sticky and has adhesive force, which may attribute to spreading the lignin on the fiber surface. It then turns back to its solid state upon cooling [37]. Another factor is the fact that some of the hemicellulose elements may also be present on the fiber surface, and it may work on binding the fiber together with PLA during compounding. This would explain the good formation structure in the tensile fracture surface of the SHS-PALF/PLA biocomposite and the improvement in the properties of the SHS-PALF/PLA biocomposite.

\subsubsection{Flexural and Impact Properties}

The results of flexural and impact tests on SHS-PALF/PLA biocomposite and PALF/PLA biocomposite with treatment temperature of $220^{\circ} \mathrm{C}$ and time of $60 \mathrm{~min}$ are shown in Table 3. It can be seen that the flexural strength, flexural modulus, and impact strength for SHS-treated biocomposite had a higher value than the untreated biocomposite. The improvement in flexural strength, flexural modulus, and impact strength was $12 \%, 7 \%$, and $16 \%$, respectively. The increase in flexural and impact properties of SHS-PALF/PLA biocomposite resulted from the improvement in the interfacial adhesion between the fiber and the matrix. Moreover, a rough fiber surface led to a better fiber-matrix interlocking and thus an enhancement in the mechanical performance of the SHS-PALF/PLA biocomposite. 
Table 3. Flexural strength, flexural modulus, and impact strength of PALF/PLA and SHS-PALF/PLA biocomposites.

\begin{tabular}{cccc}
\hline Biocomposite & Flexural Strength (MPa) & Flexural Modulus (GPa) & Impact Strength (J/m) \\
\hline PALF/PLA & $70.53 \pm 1.52$ & $5.2 \pm 0.18$ & $115.04 \pm 3.95$ \\
SHS-PALF/PLA & $79.27 \pm 0.43$ & $5.57 \pm 0.16$ & $133.73 \pm 6.49$ \\
\hline
\end{tabular}

\subsubsection{Dimensional Stability}

One of the major drawbacks in natural fiber composites is the hydrophilic nature of the natural fiber [38]. The tendency of natural fibers to absorb moisture and swell when exposed to water or humid conditions limits the application of biocomposites. Therefore, water uptake and thickness swelling experiments are very important parameters to study when working with biocomposites. Figure 5 presents the water uptake and thickness swelling of PALF/PLA and SHS-PALF/PLA biocomposites with treatment temperature of $220^{\circ} \mathrm{C}$ for $60 \mathrm{~min}$ after $24 \mathrm{~h}$ of immersion in water. Both biocomposites showed an increase in water uptake and thickness swelling due to the presence of hydroxyl groups in the fibers, which increased the amount of water absorbed into the composite [39]. However, the SHS-PALF/PLA biocomposite showed lower percentage of water uptake and thickness swelling compared to the untreated PALF/PLA biocomposite.

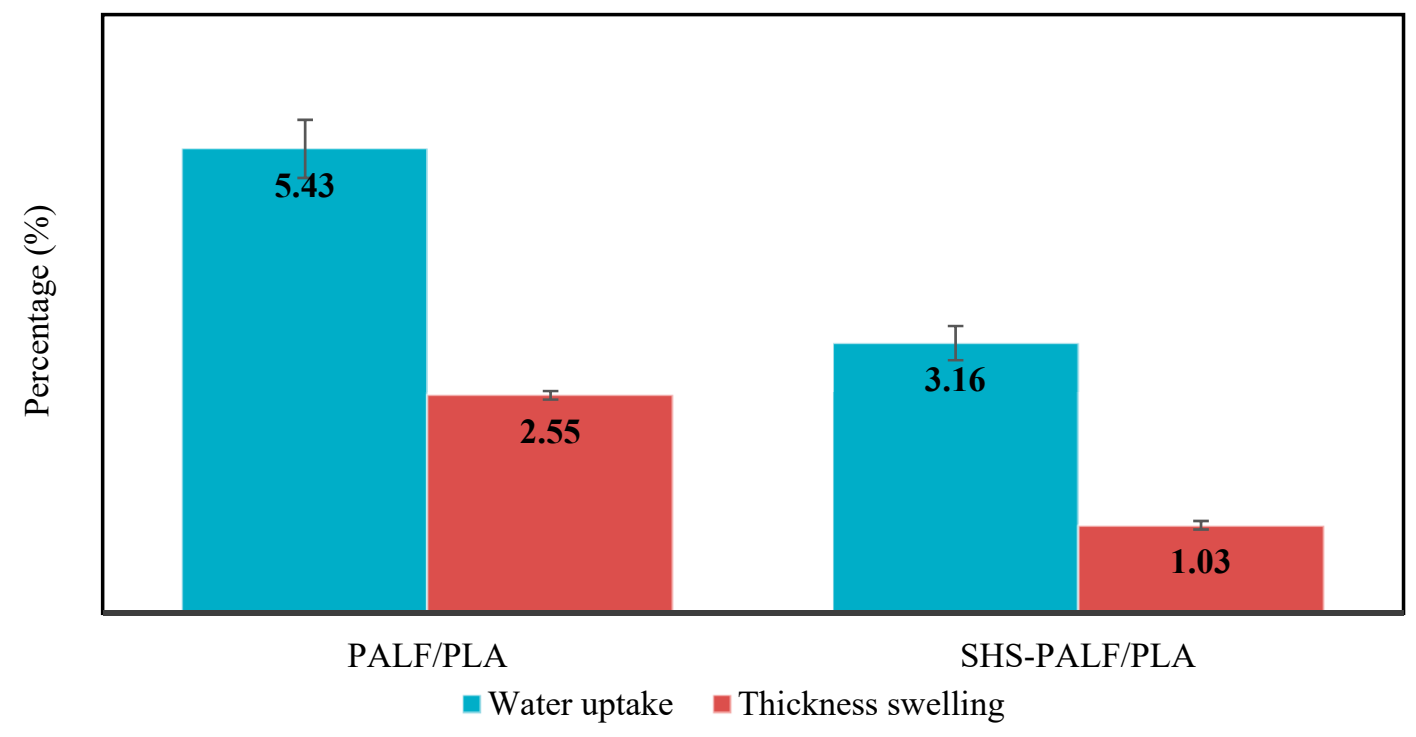

Figure 5. The water uptake and thickness swelling of PALF/PLA and SHS-PALF/PLA biocomposites.

As can be seen in Figure 5, the water uptake percentage of the SHS-PALF/PLA biocomposite decreased by $42 \%$ compared to the untreated PALF/PLA biocomposite. This result can be attributed to the removal of hemicellulose and the increase in cellulose content in the fiber as well as the decrement in the free space due to the improvement of the binding force. A similar observation was reported on the decrement of water uptake for the treated composite after alkali treatment [40]. Moreover, in this work, the water uptake of the biocomposite was not high. This can be attributed to the low fiber content in the biocomposite, where it contains $30 \mathrm{wt} \%$ of PALF. According to Muñoz et al. [41], the water uptake increases with the increase in fiber loading in the composite. The thickness swelling for the untreated PALF/PLA showed a reduction of $60 \%$ compared to SHS-PALF/PLA. This can be attributed to the low water uptake of the SHS-PALF/PLA biocomposite as the thickness swelling directly corresponds to the amount of water absorbed by the biocomposite. 


\subsubsection{X-Ray Diffraction (XRD)}

The neat PLA, untreated PALF/PLA, and SHS-PALF/PLA biocomposites were characterized by X-ray diffraction to study the effect of the untreated PALF and SHS-PALF on the neat PLA crystallinity. As shown in Figure 6, the XRD patterns for neat PLA exhibited intensity, with a broad diffraction peak appearing at approximately $2 \theta \approx 17^{\circ}$. The neat PLA did not show any characteristic peak, indicating that PLA has an amorphous structure [42]. In the case of PALF/PLA and SHS-PALF/PLA biocomposites, it can be observed that the XRD patterns exhibited two diffraction peaks at approximately $2 \theta \approx 16^{\circ}$ and $2 \theta \approx 22^{\circ}$. These two peaks can be indexed to the native cellulose crystalline structure (cellulose I), similar to the study reported by Sena Neto [25]. The presence of these two diffraction peaks can be clearly attributed to the existence of PALF in the biocomposite. In addition, the diffraction patterns of the SHS-PALF/PLA biocomposite was similar to the PALF/PLA biocomposite, indicating that the SHS treatment did not change the cellulose's crystal structure [15]. Furthermore, the intensity of the diffraction peak became stronger, confirming the increase in the crystallinity of the SHS-PALF/PLA biocomposite [9]. This result supports the improvement in the mechanical performance of the SHS-PALF/PLA biocomposite. As reported by Mathew et al. [43], higher crystallinity of composites is considered as one of the factors for better mechanical performance.

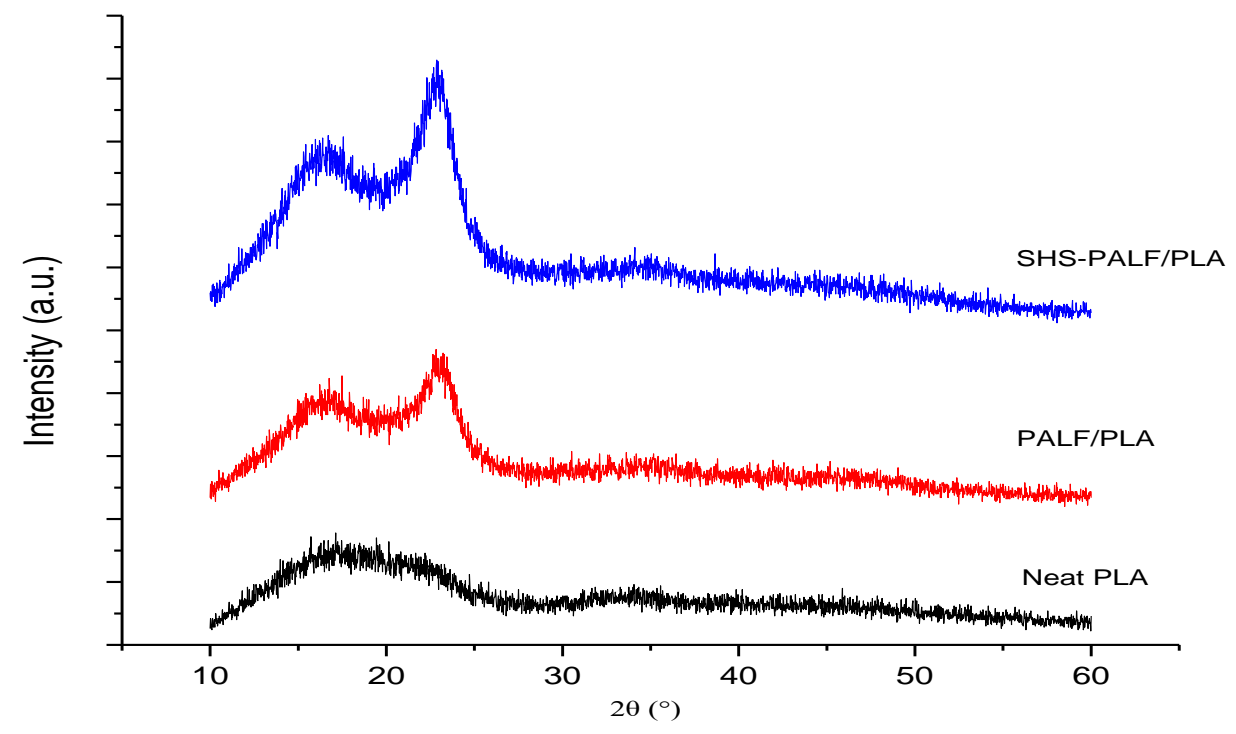

Figure 6. X-ray Diffraction (XRD) patterns of neat PLA, PALF/PLA, and SHS-PALF/PLA biocomposites.

\section{Conclusions}

In the present work, SHS was successfully used as a treatment method to modify the surface of PALF. An improvement in the roughness of the fiber surface was achieved, which can be attributed to the removal of hemicellulose and impurities. The tensile properties showed the optimum result at $220{ }^{\circ} \mathrm{C}$ for $60 \mathrm{~min}$ treatment condition. It was found that the increase in tensile strength, tensile modulus, and elongation at break were $24 \%, 16 \%$, and $14 \%$, respectively. The SEM analysis showed improvement in the interfacial adhesion of the SHS-PALF/PLA biocomposite, while the XRD graph showed the increase in the crystallinity of the biocomposite after the SHS treatment. Moreover, the flexural strength, flexural modulus, and impact were also enhanced by $12 \%, 7 \%$, and $16 \%$, respectively, for the SHS-PALF/PLA biocomposite. Dimensional stability also showed improvement in water uptake and thickness swelling of $42 \%$ and $60 \%$, respectively. This work therefore proves that SHS can be successfully used as an environmentally friendly processing method in modifying the PALF surface that can be an alternative to the conventional chemical methods that are utilized in biocomposite production. 
Author Contributions: Conceptualization, A.J.H.C., B.W.C., and N.A.I.; methodology, A.J.H.C. and B.W.C.; validation, A.J.H.C., B.W.C., and N.A.I.; resources, N.A.I. and H.A.; writing-original draft preparation, A.J.H.C.; writing-review and editing, A.J.H.C. and B.W.C.; supervision, N.A.I., B.W.C., H.A., and N.Z.; project administration, N.A.; funding acquisition, N.A. and B.W.C.

Funding: This research was funded by the Fundamental Research Grant Scheme, Ministry of Education Malaysia, grant number 5524950. The APC was funded by Universiti Putra Malaysia.

Conflicts of Interest: The authors declare no conflict of interest. The funders had no role in the design of the study; in the collection, analyses, or interpretation of data; in the writing of the manuscript; or in the decision to publish the results.

\section{References}

1. Shalwan, A.; Yousif, B.F. In state of art: Mechanical and tribological behaviour of polymeric composites based on natural fibres. Mater. Des. 2013, 48, 14-24. [CrossRef]

2. Sassoni, E.; Manzi, S.; Motori, A.; Montecchi, M.; Canti, M. Novel sustainable hemp-based composites for application in the building industry: Physical, thermal and mechanical characterization. Energy Build. 2014, 77, 219-226. [CrossRef]

3. Holbery, J.; Houston, D. Natural-fiber-reinforced polymer composites in automotive applications. Jom 2006, 58, 80-86. [CrossRef]

4. Ramli, S.N.R.; Fadzullah, S.H.S.M.; Mustafa, Z. The effect of alkaline treatment and fiber length on pineapple leaf fiber reinforced poly lactic acid biocomposites. J. Teknol. 2017, 79, 111-115. [CrossRef]

5. Asim, M.; Abdan, K.; Jawaid, M.; Nasir, M.; Dashtizadeh, Z.; Ishak, M.R.; Hoque, M.E. A review on pineapple leaves fibre and its composites. Int. J. Polym. Sci. 2015, 2015, 16. [CrossRef]

6. Jose, S.; Salim, R.; Ammayappan, L. An overview on production, properties, and value addition of pineapple leaf fibers (palf). J. Nat. Fibers 2016, 13, 362-373. [CrossRef]

7. Shih, Y.-F.; Chang, W.-C.; Liu, W.-C.; Lee, C.-C.; Kuan, C.-S.; Yu, Y.-H. Pineapple leaf/recycled disposable chopstick hybrid fiber-reinforced biodegradable composites. J. Taiwan Inst. Chem. Eng. 2014, 45, 2039-2046. [CrossRef]

8. Arib, R.M.N.; Sapuan, S.M.; Ahmad, M.M.H.M.; Paridah, M.T.; Zaman, H.M.D.K. Mechanical properties of pineapple leaf fibre reinforced polypropylene composites. Mater. Des. 2006, 27, 391-396. [CrossRef]

9. Rayung, M.; Ibrahim, N.A.; Zainuddin, N.; Saad, W.Z.; Razak, N.I.A.; Chieng, B.W. The effect of fiber bleaching treatment on the properties of poly (lactic acid)/oil palm empty fruit bunch fiber composites. Int. J. Mol. Sci. 2014, 15, 14728-14742. [CrossRef] [PubMed]

10. Jia, W.; Gong, R.H.; Hogg, P.J. Poly (lactic acid) fibre reinforced biodegradable composites. Compos. Part B Eng. 2014, 62, 104-112. [CrossRef]

11. Chieng, B.W.; Ibrahim, N.A.; Wan Yunus, W.M.Z.; Hussein, M.Z. Poly (lactic acid)/poly (ethylene glycol) polymer nanocomposites: Effects of graphene nanoplatelets. Polymers 2014, 6, 93-104. [CrossRef]

12. Kaewpirom, S.; Worrarat, C. Preparation and properties of pineapple leaf fiber reinforced poly (lactic acid) green composites. Fibers Polym. 2014, 15, 1469-1477. [CrossRef]

13. Nopparut, A.; Amornsakchai, T. Influence of pineapple leaf fiber and it's surface treatment on molecular orientation in, and mechanical properties of, injection molded nylon composites. Polym. Test. 2016, 52, 141-149. [CrossRef]

14. Then, Y.Y.; Ibrahim, N.A.; Zainuddin, N.; Ariffin, H.; Yunus, W.M.Z.W.; Chieng, B.W. Static mechanical, interfacial, and water absorption behaviors of alkali treated oil palm mesocarp fiber reinforced poly (butylene succinate) biocomposites. BioResources 2014, 10, 123-136. [CrossRef]

15. Then, Y.Y.; Ibrahim, N.A.; Zainuddin, N.; Chieng, B.W.; Ariffin, H.; Yunus, W.M.Z.W. Influence of alkaline-peroxide treatment of fiber on the mechanical properties of oil palm mesocarp fiber/poly (butylene succinate) biocomposite. BioResources 2015, 10, 1730-1746. [CrossRef]

16. Teh, C.C.; Ibrahim, N.A.; Yunus, W.M.Z.W. Response surface methodology for the optimization and characterization of oil palm mesocarp fiber-graft-poly (butyl acrylate). BioResources 2013, 8, 5244-5260. [CrossRef]

17. Huda, M.S.; Drzal, L.T.; Mohanty, A.K.; Misra, M. Effect of chemical modifications of the pineapple leaf fiber surfaces on the interfacial and mechanical properties of laminated biocomposites. Compos. Interfaces 2008, 15, 169-191. [CrossRef] 
18. Sagehashi, M.; Miyasaka, N.; Shishido, H.; Sakoda, A. Superheated steam pyrolysis of biomass elemental components and sugi (japanese cedar) for fuels and chemicals. Bioresour. Technol. 2006, 97, 1272-1283. [CrossRef] [PubMed]

19. Then, Y.Y.; Ibrahim, N.A.; Zainuddin, N.; Ariffin, H.; Yunus, W.M.Z.W.; Chieng, B.W. The influence of green surface modification of oil palm mesocarp fiber by superheated steam on the mechanical properties and dimensional stability of oil palm mesocarp fiber/poly (butylene succinate) biocomposite. Int. J. Mol. Sci. 2014, 15, 15344-15357. [CrossRef] [PubMed]

20. Bahrin, E.K.; Baharuddin, A.S.; Ibrahim, M.F.; Razak, M.N.A.; Sulaiman, A.; Aziz, S.A.; Hassan, M.A.; Shirai, Y.; Nishida, H. Physicochemical property changes and enzymatic hydrolysis enhancement of oil palm empty fruit bunches treated with superheated steam. BioResources 2012, 7, 1784-1801.

21. Mahmud, N.A.N.; Baharuddin, A.S.; Bahrin, E.K.; Sulaiman, A.; Naim, M.N.; Zakaria, R.; Hassan, M.A.; Nishida, H.; Shirai, Y. Enzymatic saccharification of oil palm mesocarp fiber (opmf) treated with superheated steam. BioResources 2013, 8, 1320-1331. [CrossRef]

22. Hosseinaei, O.; Wang, S.; Enayati, A.A.; Rials, T.G. Effects of hemicellulose extraction on properties of wood flour and wood-plastic composites. Compos. Part A Appl. Sci. Manuf. 2012, 43, 686-694. [CrossRef]

23. Nordin, N.; Ariffin, H.; Andou, Y.; Hassan, M.; Shirai, Y.; Nishida, H.; Yunus, W.; Karuppuchamy, S.; Ibrahim, N.A. Modification of oil palm mesocarp fiber characteristics using superheated steam treatment. Molecules 2013, 18, 9132-9146. [CrossRef]

24. Birnin-Yauri, A.; Ibrahim, N.A.; Zainuddin, N.; Abdan, K.; Then, Y.Y.; Chieng, B.W. Effect of maleic anhydride-modified poly (lactic acid) on the properties of its hybrid fiber biocomposites. Polymers 2017, 9, 165. [CrossRef]

25. Sena Neto, A.R.; Araujo, M.A.M.; Souza, F.V.D.; Mattoso, L.H.C.; Marconcini, J.M. Characterization and comparative evaluation of thermal, structural, chemical, mechanical and morphological properties of six pineapple leaf fiber varieties for use in composites. Ind. Crops Prod. 2013, 43, 529-537. [CrossRef]

26. Garside, P.; Wyeth, P. Identification of cellulosic fibres by ftir spectroscopy-Thread and single fibre analysis by attenuated total reflectance. Stud. Conserv. 2003, 48, 269-275. [CrossRef]

27. Sinha, E.; Rout, S. Influence of fibre-surface treatment on structural, thermal and mechanical properties of jute fibre and its composite. Bull. Mater. Sci. 2009, 32, 65. [CrossRef]

28. Dong, C.; Lv, Z.; Zhang, L.; Shen, H.; Li, N.; Zhu, P. Structure and characteristics of pineapple leaf fibers obtained from pineapple leaves. Adv. Mater. Res. 2014, 998-999, 316-319. [CrossRef]

29. Panyasart, K.; Chaiyut, N.; Amornsakchai, T.; Santawitee, O. Effect of surface treatment on the properties of pineapple leaf fibers reinforced polyamide 6 composites. Energy Proced. 2014, 56, 406-413. [CrossRef]

30. Birnin-Yauri, A.U.; Ibrahim, N.A.; Zainuddin, N.; Abdan, K.; Then, Y.Y.; Chieng, B.W. Influence of kenaf core fiber incorporation on the mechanical performance and dimensional stability of oil palm fiber reinforced poly (lactic acid) hybrid biocomposites. BioResources 2016, 11, 3332-3355. [CrossRef]

31. Siakeng, R.; Jawaid, M.; Ariffin, H.; Sapuan, S.M. Mechanical, dynamic, and thermomechanical properties of coir/pineapple leaf fiber reinforced polylactic acid hybrid biocomposites. Polym. Compos. 2018. [CrossRef]

32. Ibrahim, N.A.; Hadithon, K.A.; Abdan, K. Effect of fiber treatment on mechanical properties of kenaf fiber-ecoflex composites. J. Reinf. Plast. Compos. 2010, 29, 2192-2198. [CrossRef]

33. Li, X.; Tabil, L.G.; Panigrahi, S. Chemical treatments of natural fiber for use in natural fiber-reinforced composites: A review. J. Polym. Environ. 2007, 15, 25-33. [CrossRef]

34. Chen, J.-H.; Wang, K.; Xu, F.; Sun, R.-C. Effect of hemicellulose removal on the structural and mechanical properties of regenerated fibers from bamboo. Cellulose 2015, 22, 63-72. [CrossRef]

35. Threepopnatkul, P.; Kaerkitcha, N.; Athipongarporn, N. Effect of surface treatment on performance of pineapple leaf fiber-polycarbonate composites. Compos. Part B Eng. 2009, 40, 628-632. [CrossRef]

36. Lopattananon, N.; Payae, Y.; Seadan, M. Influence of fiber modification on interfacial adhesion and mechanical properties of pineapple leaf fiber-epoxy composites. J. Appl. Polym. Sci. 2008, 110, 433-443. [CrossRef]

37. Chen, H. Chemical composition and structure of natural lignocellulose. In Biotechnology of Lignocellulose; Hongzhang, C., Ed.; Springer: Berlin, Germany, 2014; pp. 25-71.

38. Chandrasekar, M.; Ishak, M.R.; Sapuan, S.M.; Leman, Z.; Jawaid, M. A review on the characterisation of natural fibres and their composites after alkali treatment and water absorption. Plast. Rubber Compos. 2017, 46, 119-136. [CrossRef] 
39. Väisänen, T.; Das, O.; Tomppo, L. A review on new bio-based constituents for natural fiber-polymer composites. J. Clean. Prod. 2017, 149, 582-596. [CrossRef]

40. Hosur, M.; Maroju, H.; Jeelani, S. Comparison of effects of alkali treatment on flax fibre reinforced polyester and polyester-biopolymer blend resins. Polym. Polym. Compos. 2015, 23, 229-242. [CrossRef]

41. Muñoz, E.; García-Manrique, J.A. Water absorption behaviour and its effect on the mechanical properties of flax fibre reinforced bioepoxy composites. Int. J. Polym. Sci. 2015, 2015, 10. [CrossRef]

42. Silverajah, V.S.G.; Ibrahim, N.A.; Yunus, W.M.Z.W.; Hassan, H.A.; Chieng, B.W. A comparative study on the mechanical, thermal and morphological characterization of poly (lactic acid)/epoxidized palm oil blend. Int. J. Mol. Sci. 2012, 13, 5878-5898. [CrossRef]

43. Mathew, A.P.; Oksman, K.; Sain, M. Mechanical properties of biodegradable composites from poly lactic acid (pla) and microcrystalline cellulose (mcc). J. Appl. Polym. Sci. 2005, 97, 2014-2025. [CrossRef]

(C) 2019 by the authors. Licensee MDPI, Basel, Switzerland. This article is an open access article distributed under the terms and conditions of the Creative Commons Attribution (CC BY) license (http:// creativecommons.org/licenses/by/4.0/). 